Materialia

Elsevier Editorial system(tm) for Scripta

Manuscript Draft

Manuscript Number: SMM-18-1271R1

Title: Novel Processing Route for the Fabrication of Bulk High-Entropy Metal Diborides

Article Type: Regular article

Keywords: High-entropy ceramics; Borides; Spark Plasma Sintering; Selfpropagating High-temperature Synthesis; X-ray diffraction (XRD) .

Corresponding Author: Dr. Roberto Orru', PhD

Corresponding Author's Institution: University of Cagliari

First Author: Giovanna Tallarita

Order of Authors: Giovanna Tallarita; Roberta Licheri, PhD; Sebastiano Garroni, PhD; Roberto Orru', PhD; Giacomo Cao, PhD

Abstract: A single high-entropy phase material with hexagonal structure is produced by a two-steps processing method. Elemental reactants are first remarkably converted by Self-propagating High-temperature Synthesis (SHS). The completion of the chemical transformation to the desired (Hf0.2Mo0.2Ta0.2Nb0.2Ti0.2)B2 phase and its concurrent consolidation up to $92.5 \%$ relative density is achieved by processing the sHS powders at $1950^{\circ} \mathrm{C}$ via Spark Plasma Sintering. It is clearly evidenced that the use of the SHS technique is extremely beneficial to promote the formation of high-entropy ceramics, as compared to the time consuming ball milling treatment alternatively adopted. 

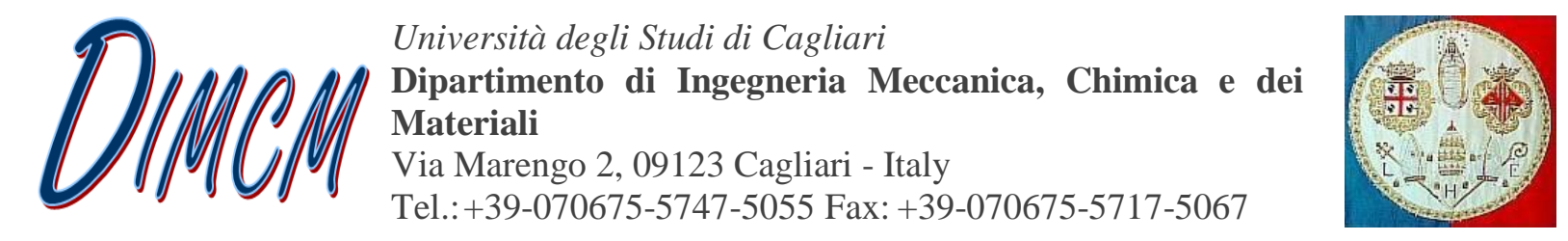

Cagliari, 22-08-2018

Dear Editor,

please find in the attached file our replies to the comments raised by the Reviewer regarding our manuscript "Novel Processing Route for the Fabrication of Bulk High-Entropy Metal Diborides” by G. Tallarita, R. Licheri, S. Garroni, R. Orrù, and G. Cao, submitted for publication in Scripta Materialia. In particular, the reason why no property is measured at this stage on the obtained material, which represents the only criticism raised by the Reviewer, is explained. Nonetheless, some literature data and related comments have been introduced in the Revised Version of the manuscript here attached.

Please find also enclosed the Revised Marked Version of the paper where the changes with respect to the first version have been highlighted in red character.

Your sincerely,

Dr. Roberto Orrù

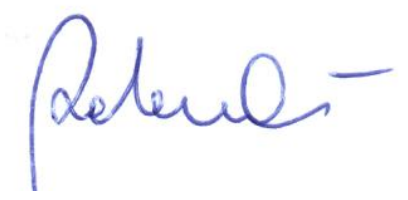

Professor 
Graphical abstract

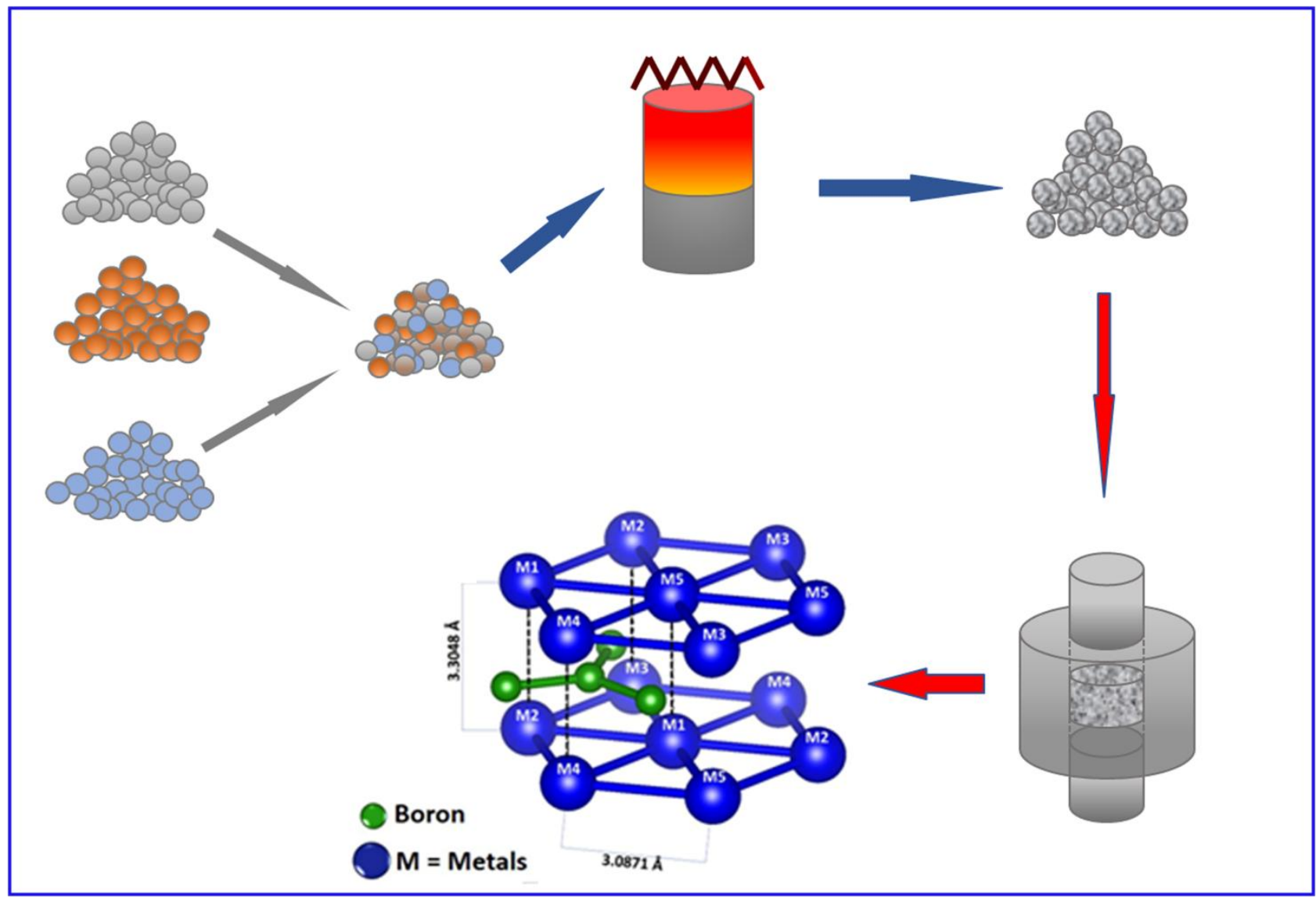




\section{$\underline{\text { Replies to the Reviewer's comments }}$}

First, we would like to thank the Reviewer for his/her positive comments on our paper and for recommending its publication after minor revision.

The main reason why no property was measured on the obtained product is because at this stage we mostly focused our attention on the use of a more efficient fabrication route for producing HEBs with respect to the state of the art, which represents the novelty of this work, as also clearly evidenced in the Reviewer's comments. On the other hand, the specific system under investigation was already produced as a single phase at UCSD.

Of course, we agree with the Reviewer that the measure of some crucial properties is an essential step for the validation of the HEB material. However, since the full product densification is far from being achieved, we are currently optimizing the most relevant operating parameters, namely particles size of SHS powders and SPS process conditions, to try to further reduce residual porosity in the bulk material. Subsequently, a detailed activity to determine mechanical, oxidation resistance, optical, and other properties is clearly planned to be performed on the optimal product.

Unfortunately, such data are not available yet, so that, to meet the Reviewer's suggestion, we took advantage of the fact that the material produced in the present work by SHS-SPS shows a relative density very similar to the value obtained by Gild et al. (2016) for the same system, i.e. about 92.5 and $92.2 \%$, respectively. Thus, the corresponding properties measured in the latter study (i.e. hardness and oxidation resistance), which are expected to be rather similar to those ones associated to the SHS-SPS product, have been reported and discussed in this work.

All the considerations above have been introduced in the Revised Version of the manuscript. 
1

\title{
Novel Processing Route for the Fabrication of Bulk High-Entropy Metal Diborides
}

\author{
Giovanna Tallarita ${ }^{1}$, Roberta Licheri $^{1}$, Sebastiano Garroni ${ }^{2-3}$, Roberto Orrù ${ }^{1, *}$, Giacomo \\ $\mathrm{CaO}^{1}$ \\ ${ }^{1}$ Dipartimento di Ingegneria Meccanica, Chimica, e dei Materiali, Università degli Studi \\ di Cagliari, via Marengo 2, 09123 Cagliari, Italy \\ ${ }^{2}$ International Research Centre in Critical Raw Materials-ICCRAM, University of Burgos, Plaza Misael \\ Bañuelos s/n, 09001 Burgos, Spain \\ ${ }^{3}$ Advanced Materials, Nuclear Technology and Applied Bio/Nanotechnology, Consolidated Research \\ Unit UIC-154, University of Burgos, Hospital del Rey s/n, 09001 Burgos, Castilla y Leon, Spain
}

\begin{abstract}
A single high-entropy phase material with hexagonal structure is produced by a two-steps processing method. Elemental reactants are first remarkably converted by Self-propagating High-temperature Synthesis (SHS). The completion of the chemical transformation to the desired $\left(\mathrm{Hf}_{0.2} \mathrm{Mo}_{0.2} \mathrm{Ta}_{0.2} \mathrm{Nb}_{0.2} \mathrm{Ti}_{0.2}\right) \mathrm{B}_{2}$ phase and its concurrent consolidation up to $92.5 \%$ relative density is achieved by processing the SHS powders at $1950^{\circ} \mathrm{C}$ via Spark Plasma Sintering. It is clearly evidenced that the use of the SHS technique is extremely beneficial to promote the formation of high-entropy ceramics, as compared to the time consuming ball milling treatment alternatively adopted.
\end{abstract}

Keywords: High-entropy ceramics; Borides; Spark Plasma Sintering; Self-propagating Hightemperature Synthesis; X-ray diff raction (XRD).

* Corresponding author: Roberto Orrù - roberto.orru@ dimcm.unica.it 
The growing interest in Ultra-High Temperature Ceramics (UHTCs) based on transition metal diborides is readily justified by their unusual combination of attractive physico-chemical properties, such as melting temperature exceeding $3000 \mathrm{~K}$, high hardness, chemical inertness, good electrical and thermal conductivity, intrinsic solar selectivity, low neutron absorption, etc. [1]. Aerospace (wing leading edges, nosetips, etc.), solar energy (receivers for concentrating solar power plants), nuclear reactors, metallurgy (molten metal crucibles), cutting tools, microelectronics, etc., are only few examples of application fields where UHTCs are extremely desirable. In spite of this, a suitable diffusion of such material family is not reached yet, due to their relatively low fracture toughness and not adequate high temperature oxidation properties, other than because of the difficulties encountered for the obtainment of highly dense bodies.

In this context, a new emerging class of UHTCs, the so called High-Entropy Borides (HEBs) was recently developed at the University of California, San Diego (USA) [2]. HEBs belong to the more general family of high-entropy alloys, where metallic elements are properly combined in near equimolar ratios to generate new crystalline solid-solutions characterized by a maximum configurational entropy $\Delta S_{\text {mix }}=R \cdot \ln N$, where $R$ and $N$ are the gas constant and the total number of the equimolar components, respectively [3]. The strong interest in these materials stems from the improved thermal stability and strengthening they usually exhibit with respect to conventional alloys [3-5].

So far, the research activity in this field has been mostly focused on metallic phases, whereas only few and recent studies are available on high-entropy ceramics, either oxides [6-10] or non oxides [2,1115].

As for non oxides high entropy ceramics, six types of five-components HEBs have been prepared by Gild et al. [2]. The adopted process basically consisted of a co-milling treatment of their individual $\mathrm{MeB}_{2}$ constituents $(\mathrm{Me}=\mathrm{Zr}, \mathrm{Hf}, \mathrm{Ta}, \mathrm{Ti}, \mathrm{Mo}, \mathrm{Nb}, \mathrm{Cr})$ combined in equimolar proportions and the resulting powders were densified for $5 \mathrm{~min}$ by SPS at $2000^{\circ} \mathrm{C}$ and $30 \mathrm{MPa}$. The obtained products were single-phase materials, up to $92.4 \%$ dense, which display higher hardness and oxidation resistance as compared to the average properties of individual components fabricated and tested under the same conditions. Improved performances (hardness and thermal stability) were also reported when considering of HEB thin films prepared by non-reactive physical vapor deposition [13]. Similar findings were also obtained when characterizing the $99 \%$ dense equiatomic high-entropy carbides, namely (Hf$\mathrm{Ta}-\mathrm{Zr}-\mathrm{Nb}) \mathrm{C}$, produced very recently via SPS $\left(2300^{\circ} \mathrm{C}\right)$ from ball milled powders [11].

The major concern related to the previously mentioned fabrication methods is represented by the intense mechanical pre-treatment of the powder mixture requested to induce the formation of a single 
phase product during the subsequent densification stage. For instance, Gild et al [2] processed the diborides mixture for $6 \mathrm{~h}$ by high energy ball milling before SPS. Moreover, the duration of the mechanical treatment was even longer $(24 \mathrm{~h})$ for the fabrication of high-entropy carbides [11].

As a consequence, the corresponding whole processing time becomes very long. Furthermore, the extremely abrasive character of transition metal diborides and carbides makes the related powders prone to be contaminated from milling media, which certainly represents a crucial issue.

In this work, an alternative, more efficient, two-step processing method, consisting of the Selfpropagating High-temperature Synthesis (SHS) of the high entropy product followed by the SPS of the resulting powders, is proposed. While the latter approach was already successfully exploited for the obtainment of various standard monophasic and composite UHTCs [16], it is the first time that crystalline high entropy ceramics are produced following such route.

SHS experiments were performed starting from Hf (Alfa Aesar, cod. 00337, particle size $<44 \mu \mathrm{m}$,

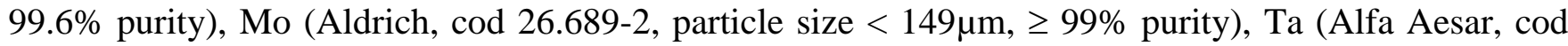

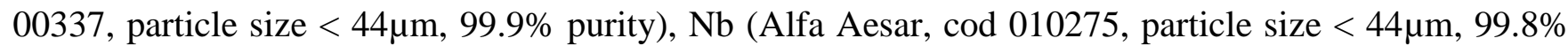

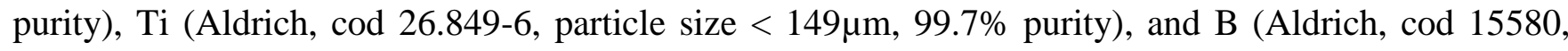
amorphous, $\geq 99 \%$ purity) powders. Mixing of reactants was carried out according to the following reactions stoichiometry:

$$
0.2 \mathrm{Hf}+0.2 \mathrm{Mo}+0.2 \mathrm{Ta}+0.2 \mathrm{Nb}+0.2 \mathrm{Ti}+(2+\mathrm{x}) \mathrm{B} \rightarrow\left(\mathrm{Hf}_{0.2} \mathrm{Mo}_{0.2} \mathrm{Ta}_{0.2} \mathrm{Nb}_{0.2} \mathrm{Ti}_{0.2}\right) \mathrm{B}_{2}
$$

The use of a slight excess of $\mathrm{B}(\mathrm{x}=0.2)$ with respect to the stoichiometric value allows for, in agreement to previous studies related to the obtainment of individual metal diborides [17-18], the removal of oxide impurities initially present in the raw powders. SHS experiments were conducted inside a closed stainless steel vessel under Argon atmosphere using cylindrical pellets (10 mm diameter and $30 \mathrm{~mm}$ high) obtained after cold-pressing about $10 \mathrm{~g}$ of the reactants mixture. The reaction was activated at one pellet end using an electrically heated tungsten coil.

The SHS product was pulverized after a short $(20 \mathrm{~min})$ ball milling treatment using a SPEX 8000 (SPEX CertiPrep, USA) shaker device with a ball-to-powder weight ratio of 2. Particle size of the resulting powders was evaluated by laser light scattering analysis (CILAS 1180, France). Their consolidation was carried out by SPS (515S model, Fuji Electronic Industrial Co., Ltd., Kanagawa, Japan) at $1950^{\circ} \mathrm{C}$ for 20 min under a mechanical pressure of $20 \mathrm{MPa}$ and vacuum conditions. Disks of about $14.7 \mathrm{~mm}$ diameter and $3 \mathrm{~mm}$ thickness were obtained. Details on the SPS apparatus and procedure can be found elsewhere [17-18]. 
Compositional and structural characterization of the SHS and SPS products was performed by X-ray diffraction analysis (Philips PW 1830, Netherlands) using $\mathrm{Cu} K_{\alpha}$ radiation, over a range of scattering angles $2 \theta$ from 20 to 130 , in steps of $0.05^{\circ}$ with $15 \mathrm{~s}$ acquisition time per angle. The XRD patterns were analyzed by the Rietveld method using the MAUD program to determine and quantify the phases content and the corresponding microstructural parameters [19]. In addition, the compositional uniformity in sintered samples was assessed by examining their cross section by high resolution scanning electron microscopy (HRSEM) (mod. S4000, Hitachi, Tokyo, Japan) equipped with a UltraDry EDS Detector (Thermo Fisher Scientific, Waltham, MA, USA).

As schematically represented in Figure 1, the first processing stage consists in the preparation of $\left(\mathrm{Hf}_{0.2} \mathrm{Mo}_{0.2} \mathrm{Ta}_{0.2} \mathrm{Nb}_{0.2} \mathrm{Ti}_{0.2}\right) \mathrm{B}_{2}$ by SHS according to reaction (1). The initial mixture, containing the starting reagents, has been analyzed by XRD. The pattern integrated with the Rietveld analysis is reported in Figure 2a, and it confirms the presence of the all metals with the expected concentration (see Table 1). Bragg reflections of Boron cannot be detected in this pattern because its amorphous nature and the low scattering, if compared with the other heavy metals. Upon ignition, the reaction front displayed a self-sustaining character with a measured maximum temperature of about $2000^{\circ} \mathrm{C}$ and average velocity of $4.75 \pm 0.25 \mathrm{~mm} / \mathrm{s}$. Such behavior was similar to that observed when the individual diborides were synthesized by SHS, for instance $\mathrm{HfB}_{2}$ [17], $\mathrm{TaB}_{2}$ [18] and $\mathrm{TiB}_{2}$ [20], and is consistent with their high enthalpies of formation $\left(-\Delta \mathrm{H}_{\mathrm{f}}^{0}\right)$, i.e. $335.975,209.200$ and $323.800 \mathrm{~kJ} / \mathrm{mol}$, respectively [21].

The particle size parameters of the powders obtained after the SHS products was comminuted by 20 min ball milling treatment are $\mathrm{d}_{10}=0.23 \pm 0.02 \mu \mathrm{m}, \mathrm{d}_{50}=1.94 \pm 0.14 \mu \mathrm{m}, \mathrm{d}_{90}=9.82 \pm 0.39 \mu \mathrm{m}$, and $\mathrm{d}_{\mathrm{av}}=3.71 \pm 0.20 \mu \mathrm{m}$. The XRD pattern of the synthesized powders is reported in Figure $\mathbf{2 b}$ along with the related best fit profile. The resulting compositional and microstructural data, as determined by Rietveld analysis, are summarized in Table 1. The reported results clearly indicate that a high conversion (about 96 wt.\%) of starting reactants to the desired phase was achieved by SHS. However, minor amounts of other diborides $\left(\left(\mathrm{Ta}_{0.5} \mathrm{Ti}_{0.5}\right) \mathrm{B}_{2},\left(\mathrm{Hf}_{0.5} \mathrm{Ti}_{0.5}\right) \mathrm{B}_{2}\right.$ and $\left.\mathrm{HfB}_{2}\right)$ and traces of metal oxides $\left(\mathrm{HfO}_{2}\right)$ have been also detected. The formation of the expected high-entropy solid solution ( $\mathrm{SG}=P 6 / \mathrm{mmm}$ ), nominally indicated by the formula reported in Eq. 1, can be proved by a direct comparison of the corresponding cell parameters reported in Table 1 with those ones provided by Gild et al. [2]. Nonetheless, as evidenced above, the obtainment of a single phase product was not fully achieved by SHS.

The combustion synthesized powders were then processed for $20 \mathrm{~min}$ at $1950^{\circ} \mathrm{C}$ by SPS. The XRD pattern of the cross section of the sintered sample is also shown in Figure 2c with the corresponding 
best-fit, while the related data are reported in Table 1. The obtained results indicated that the SPS treatment induced some compositional changes in the processing sample. More important is the fact that such transformations lead to massive product with neither secondary nor asymmetric peaks detected by XRD analysis. So, ultimately, a single phase material was finally obtained by SPS, as determined by the Rietveld analysis. It should be noted that XRD results for the sintered material are very similar to those ones reported by Gild et al. [2] for the same system. This confirms the formation of the high-entropy alloy characterized by 2D layers of metal cations, as schematically represented in Figure 2d [22]. The estimated value for the theoretical density of the HEB system under investigation, i.e. $8.56 \mathrm{~g} / \mathrm{cm}^{3}$, comparable to that one obtained by Gild et al. [2] $\left(8.67 \mathrm{~g} / \mathrm{cm}^{3}\right)$, further supports the latter statement. As a difference, it should be noted that the minor secondary phases evidenced in the latter study by XRD, and attributed to stable $\mathrm{HfO}_{2}$ and $\mathrm{ZrO}_{2}$, were not detected in the bulk sample produced in the present work. It is likely that the SHS process, and the corresponding conditions specifically adopted in the present investigation (excess of boron in Eq. 1), are highly beneficial in this regard. This holds also true when considering the traces $(0.1 \mathrm{wt} . \%)$ of $\mathrm{HfO}_{2}$ detected in SHS powders (Figure 2b) which are entirely eliminated during the subsequent SPS stage because of the likely presence of residual unreacted Boron. The end product reached relative density levels up to $92.5 \%$, comparable to the best values reported in Gild et al. [2]. The good densification as well as the uniform composition achieved is in agreement with the cross-sectional SEM micrograph reported in Figure 3 along with the related EDX maps. In particular, the latter ones testify that all the elements are very homogeneously distributed across the sample, with no specific evidence of preferential aggregation phenomena.

On the basis of the results discussed in this work, it is possible to state the SHS method represents a suitable tool for obtaining powders to be processed by SPS for the fabrication of innovative high entropy ceramics. In this regard, it is worth to mention the two key motivations generally provided to explain the high sintering ability displayed by UHTC powders when produced by SHS. The first one is related to the high defect concentrations associated to the extreme process conditions (heating and cooling rates on the order of $10^{5}$ and $10^{3} \mathrm{~K} / \mathrm{min}$, respectively) encountered during the fast propagation of the synthesis front [23]. In addition, when ceramic composites are synthesized, it is observed that stronger interfacial bonds are established between the fine grains of the different phases simultaneously formed in-situ, which lead to a reduction of the diffusion distances [24]. These aspects are also expected to play a beneficial role in promoting the atomic diffusion in SHS powders for the formation of the single phase HEBs during the SPS stage. It important to mention the fact that experiments conducted using the Reactive Spark Plasma Sintering (R-SPS) route, where the product synthesis and its consolidation are performed in a single 
stage as an alternative to the two steps SHS-SPS technique, did not allow us to reach the desired target. In addition, the R-SPS approach is often not appropriate when, as in the present case, strongly exothermic systems are taken into account, since various problems are usually encountered when the synthesis process occurs under the combustion regime inside a closed powder container [25].

Since the single phase material produced in the present work by SHS-SPS displays a relative density very close to that obtained by Gild et al. [2] for the same system, i.e. 92.5 and $92.2 \%$, respectively, it is expected that the corresponding properties will be also similar. In particular, a higher hardness was reported for the $\left(\mathrm{Hf}_{0.2} \mathrm{Mo}_{0.2} \mathrm{Ta}_{0.2} \mathrm{Nb}_{0.2} \mathrm{Ti}_{0.2}\right) \mathrm{B}_{2}$ material $(22.5 \pm 1.7 \mathrm{GPa})$ with respect to the average value of the individual metal diborides $(19.2 \pm 1.3 \mathrm{GPa})$ [2]. Improved oxidation resistance characteristics were also observed, based on the weight gains measured during isothermal tests conducted in the range 1000$1200^{\circ} \mathrm{C}$ for $1 \mathrm{~h}$ under flowing dry air, i.e. $\left(\mathrm{Hf}_{0.2} \mathrm{Mo}_{0.2} \mathrm{Ta}_{0.2} \mathrm{Nb}_{0.2} \mathrm{Ti}_{0.2}\right) \mathrm{B}_{2}<\mathrm{HfB}_{2}<\mathrm{TaB}_{2}<\mathrm{NbB}_{2}<\mathrm{TiB}_{2}$ [2]. Of course, the potential of this HEB for industrial applications can be better defined when residual porosity of the bulk sample will be reduced, so that the mechanical properties and oxidation resistance could be correspondingly improved. Thus, future work will be specifically addressed to the optimization of the SHS-SPS process conditions particularly aimed to further increase the relative density of the sintered material. The resulting product will be then subjected to a comprehensive characterization from the microstructural, mechanical, thermal, optical, etc., points of view, to possibly identify one or more suitable applications for this material.

In summary, our study demonstrates for the first time the feasibility of the fabrication of high entropy ceramics by coupling the SHS and SPS techniques. In particular, it is found that the $\left(\mathrm{Hf}_{0.2} \mathrm{Mo}_{0.2} \mathrm{Ta}_{0.2} \mathrm{Nb}_{0.2} \mathrm{Ti}_{0.2}\right) \mathrm{B}_{2}$ system was not obtained as a single phase by SHS, albeit a high conversion level (96 wt.\%) of the elemental reactants to the desired phase was reached. Nonetheless, when the resulting SHS powders were processed by SPS, a single phase bulk material was produced. The proposed process is undoubtedly more advantageous as compared to that adopted so far, where an intense mechanical pre-treatment of the individual borides was required before SPS. This feature certainly opens interesting perspectives for the exploitation of the huge potential of high entropy ceramics systems in both innovative and traditional fields.

\section{Acknowledgements}

One of the authors (G.T.) performed her activity in the framework of the International PhD in Innovation Sciences and Technologies at the University of Cagliari, Italy. 


\section{References}

[1] W.G. Fahrenholtz, G.E. Hilmas, Scripta Mater. 129 (2017) 94.

[2] J. Gild, Y. Zhang, T. Harrington, S. Jiang, T. Hu, M.C. Quinn, W.M. Mellor, N. Zhou, K. Vecchio, J. Luo, Sci. Rep. 6 (2016) 37946.

[3] Y.F. Ye, Q. Wang, J. Lu, C.T. Liu, Y. Yang, Mater. Today 19 (2016) 349

[4] D.B. Miracle, O.N. Senkov, Acta Mater. 122 (2017) 448.

[5] J. Chen, X. Zhou, W. Wang, B. Liu, Y. Lv, W. Yang, D. Xu, Y. Liu, J. Alloy. Compd. 760 (2018) 15.

[6] C.M. Rost, E. Sachet, T. Borman, A. Moballegh, E.C. Dickey, D. Hou, J.L. Jones, S. Curtarolo, J.P. Maria, Nat. Commun. 6 (2015) art. no. 8485;

[7] D. Bérardan, S. Franger, D. Dragoe, A.K. Meena, N. Dragoe, Phys. Status Solidi RRL 10 (2016) 328.

[8] D. Bérardan, S. Franger, A.K. Meena, N. Dragoe, J. Mater. Chem. A 4 (2016) 9536.

[9] J. Gild, M. Samiee, J.L. Braun, T. Harrington, H. Vega, P.E. Hopkins, K. Vecchio, J. Luo, J. Eur. Ceram. Soc. 38 (2018) 3578.

[10] S. Jiang, T. Hu, J. Gild, N. Zhou, J. Nie, M. Qin, T. Harrington, K. Vecchio, J. Luo, Scripta Mater. 142 (2018) 116.

[11] M. Castle, T. Csanádi, S. Grasso, J. Dusza, M. Reece, Sci. Rep. 8 (2018) 8609

[12] J. Dusza, P. Švec, V. Girman, R. Sedlák, E.G. Castle, T. Csanádi, A. Kovalčíková, M.J. Reece, J. Eur. Ceram. Soc. 38 (2018) 4303.

[13] P.H. Mayrhofer, A. Kirnbauer, P. Ertelthaler, C.M. Koller, Scripta Mater. 149 (2018) 93.

[14] Y.-P. Wang, G.-Y. Gan, W. Wang, Y. Yang, B.-Y. Tang, Phys. Status Solidi B (2018) 1800011 doi:10.1002/pssb.201800011

[15] X. Yan, L. Constantin, Y. Lu, J.-F. Silvain, M. Nastasi, B. Cui, J. Am. Ceram. Soc. (2018) doi: $0.1111 /$ jace. 15779

[16] R. Orrù, G. Cao, Materials 6 (2013) 1566.

[17] C. Musa, R. Orrù, D. Sciti, L. Silvestroni, G. Cao, J. Eur. Ceram. Soc. 33 (2013) 603.

[18] R. Licheri, C. Musa, R. Orrù, G. Cao, D. Sciti, L. Silvestroni, J. Alloy. Compd. 663 (2016) 351.

[19] L. Lutterotti, R. Ceccato, R. Dal Maschio, E. Pagani, Mater. Sci. Forum 87 (1998) 278.

[20] E. Sani, M. Meucci, L. Mercatelli, A. Balbo, C. Musa, R. Licheri, R. Orrù, G. Cao, Sol. Energy Mater Sol. Cells 169 (2017) 313.

[21] I. Barin, Thermochemical data of pure substances. VHC, Weinheim, Germany, 1989. 
[22] K. Momma, F. Izumi, J. Appl. Crystallogr. 44 (2011) 1272.

[23] S.K. Mishra, S. Das, L.C. Pathak, Mater. Sci. Eng. A 364 (2004) 249.

[24] R. Licheri, R. Orrù, C. Musa, G. Cao, Mater. Lett. 62 (2008) 432.

[25] R. Licheri, C. Musa, R. Orrù, G. Cao, J. Eur. Ceram. Soc. 35 (2015) 1129. 


\section{Figure captions}

Fig. 1. Schematic representation of the processing route adopted for the fabrication of high entropy ceramics.

Fig. 2. XRD patterns and related Rietveld refinements of a) the initial reactants mixture, b) SHS powders and c) SPS bulk product. d) Scheme of the atomic crystal structure of the high entropy alloy synthesized. The unit cell was designed by VESTA software [22].

Fig. 3. Cross sectional SEM micrograph and related EDX elemental maps of the HEB sample produced by SPS 


\begin{tabular}{|c|c|c|c|c|c|c|c|c|c|c|}
\hline \multicolumn{11}{|c|}{ Initial Reactants } \\
\hline Phase & $\%$ & $\mathbf{a}(\AA)$ & b $(\AA)$ & c $(\AA)$ & $\beta\left({ }^{\circ}\right)$ & Symmetry & $\begin{array}{l}\text { Space } \\
\text { Group }\end{array}$ & $\begin{array}{c}\text { Crystallite size } \\
\text { (Å) }\end{array}$ & Microstrain & $\begin{array}{c}\text { Unit cell } \\
\text { volume }\left(\AA^{3}\right)\end{array}$ \\
\hline $\mathrm{Ti}$ & 21.0 & 3.3075 & 3.3075 & 3.3075 & 90.00 & Cubic & $\mathrm{Im}-3 \mathrm{~m}$ & 1985 & 0.0008 & 36.1826 \\
\hline $\mathrm{Ta}$ & 20.9 & 3.3185 & 3.3185 & 3.3185 & 90.00 & Cubic & Im-3m & 18159 & 0.0034 & 36.5448 \\
\hline Mo & 20.2 & 3.1476 & 3.1476 & 3.1476 & 90.00 & Cubic & Im-3m & 1441 & 0.0002 & 31.1845 \\
\hline $\mathrm{Hf}$ & 19.1 & 3.2006 & 3.2006 & 5.0705 & 90.00 & Hexagonal & $\mathrm{P} 63 / \mathrm{mmc}$ & 1125 & 0.0013 & 44.9826 \\
\hline $\mathrm{Nb}$ & 18.8 & 3.3404 & 3.3404 & 3.3404 & 90.00 & Cubic & Im-3m & 232 & 0.0001 & 37.2731 \\
\hline \multicolumn{11}{|c|}{ SHS powders } \\
\hline Phase & $\%$ & $\mathbf{a}(\AA)$ & b $(\AA)$ & c $(\AA)$ & $\boldsymbol{\beta}\left({ }^{\circ}\right)$ & Symmetry & $\begin{array}{l}\text { Space } \\
\text { Group }\end{array}$ & $\begin{array}{c}\text { Crystallite size } \\
\text { (Å) }\end{array}$ & Microstrain & $\begin{array}{c}\text { Unit cell } \\
\text { volume }\left(\AA^{3}\right)\end{array}$ \\
\hline$\left(\mathrm{Hf}_{0.2} \mathrm{Mo}_{0.2} \mathrm{Ta}_{0.2} \mathrm{Nb}_{0.2} \mathrm{Ti}_{0.2}\right) \mathrm{B}_{2}$ & 96.2 & 3.1001 & 3.1001 & 3.3127 & 90.00 & Hexagonal & P6/mmm; & 300 & 0.0044 & 27.5717 \\
\hline$\left(\mathrm{Ta}_{0.5} \mathrm{Ti}_{0.5}\right) \mathrm{B}_{2}$ & 2.3 & 3.0819 & 3.0819 & 3.2526 & 90.00 & Hexagonal & P6/mmm; & 1000 & 0.0073 & 26.7546 \\
\hline$\left(\mathrm{Hf}_{0.5} \mathrm{Ti}_{0.5}\right) \mathrm{B}_{2}$ & 0.9 & 3.1098 & 3.1098 & 3.4063 & 90.00 & Hexagonal & P6/mmm; & 1057 & 0.0052 & 28.5285 \\
\hline $\mathrm{HfB}_{2}$ & 0.5 & 3.1480 & 3.1480 & 3.4831 & 90.00 & Hexagonal & P6/mmm; & 1126 & 0.0014 & 29.8928 \\
\hline $\mathrm{HfO}_{2}$ & 0.1 & 5.1135 & 5.1345 & 5.4033 & 99.35 & Monoclinic & P21/c:b1 & 248 & 0.0019 & 139.9803 \\
\hline \multicolumn{11}{|c|}{ SPS product } \\
\hline Phase & $\%$ & $\mathbf{a}(\AA)$ & b $(\AA)$ & $\mathbf{c}(\AA)$ & $\beta\left({ }^{\circ}\right)$ & Symmetry & $\begin{array}{l}\text { Space } \\
\text { Group }\end{array}$ & $\begin{array}{c}\text { Crystallite size } \\
\text { (Å) }\end{array}$ & Microstrain & $\begin{array}{c}\text { Unit cell } \\
\text { volume }\left(\AA^{3}\right)\end{array}$ \\
\hline$\left(\mathrm{Hf}_{0.2} \mathrm{Mo}_{0.2} \mathrm{Ta}_{0.2} \mathrm{Nb}_{0.2} \mathrm{Ti}_{0.2}\right) \mathrm{B}_{2}$ & 100 & 3.0878 & 3.0878 & 3.3099 & 90.00 & Hexagonal & $\mathrm{P} 6 / \mathrm{mmm}$ & 869 & 0.0015 & 27.3303 \\
\hline
\end{tabular}




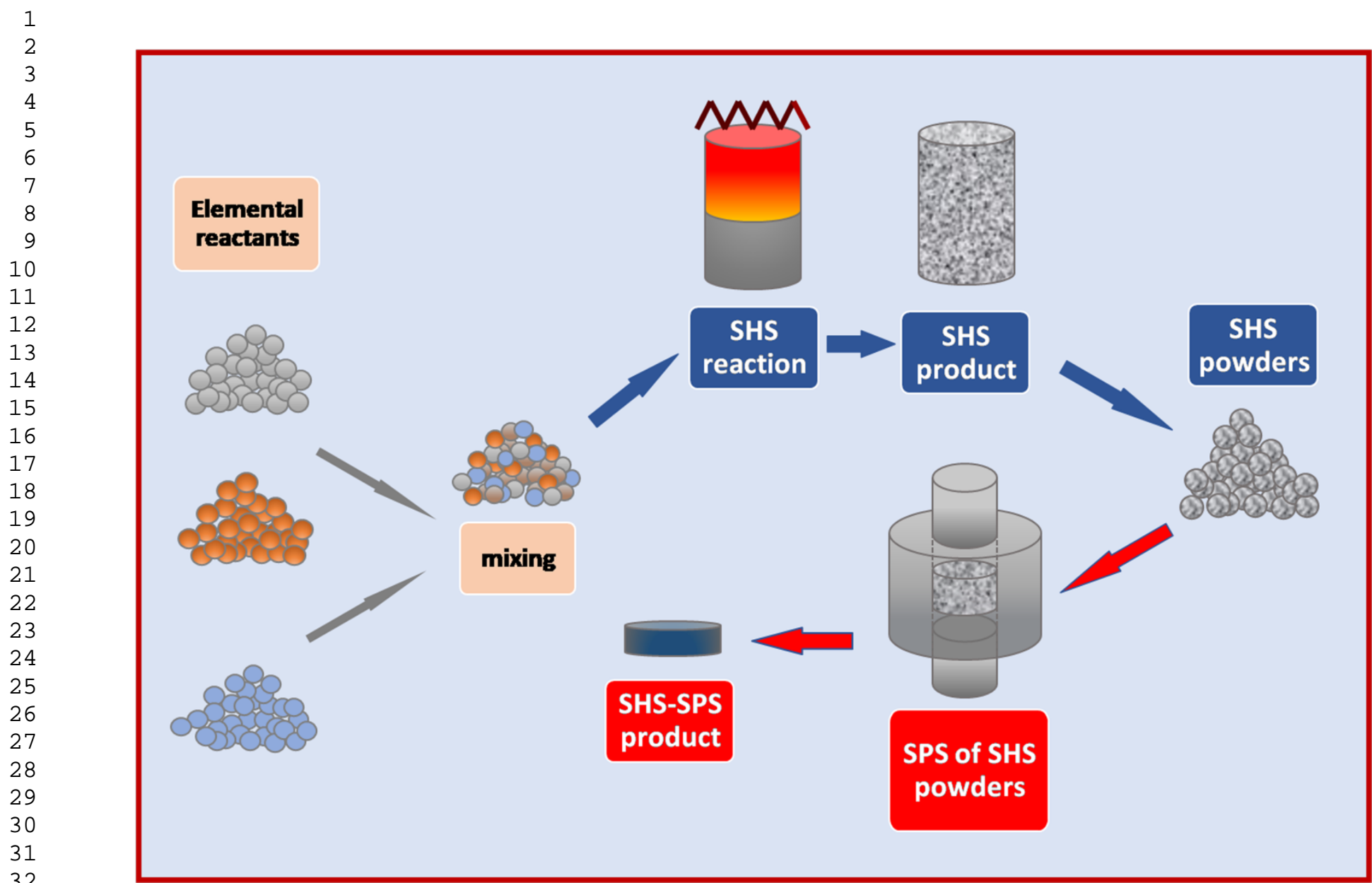

Fig. 1 
2

3

4

5

6

7

8

9

10

11

12

13

14

15

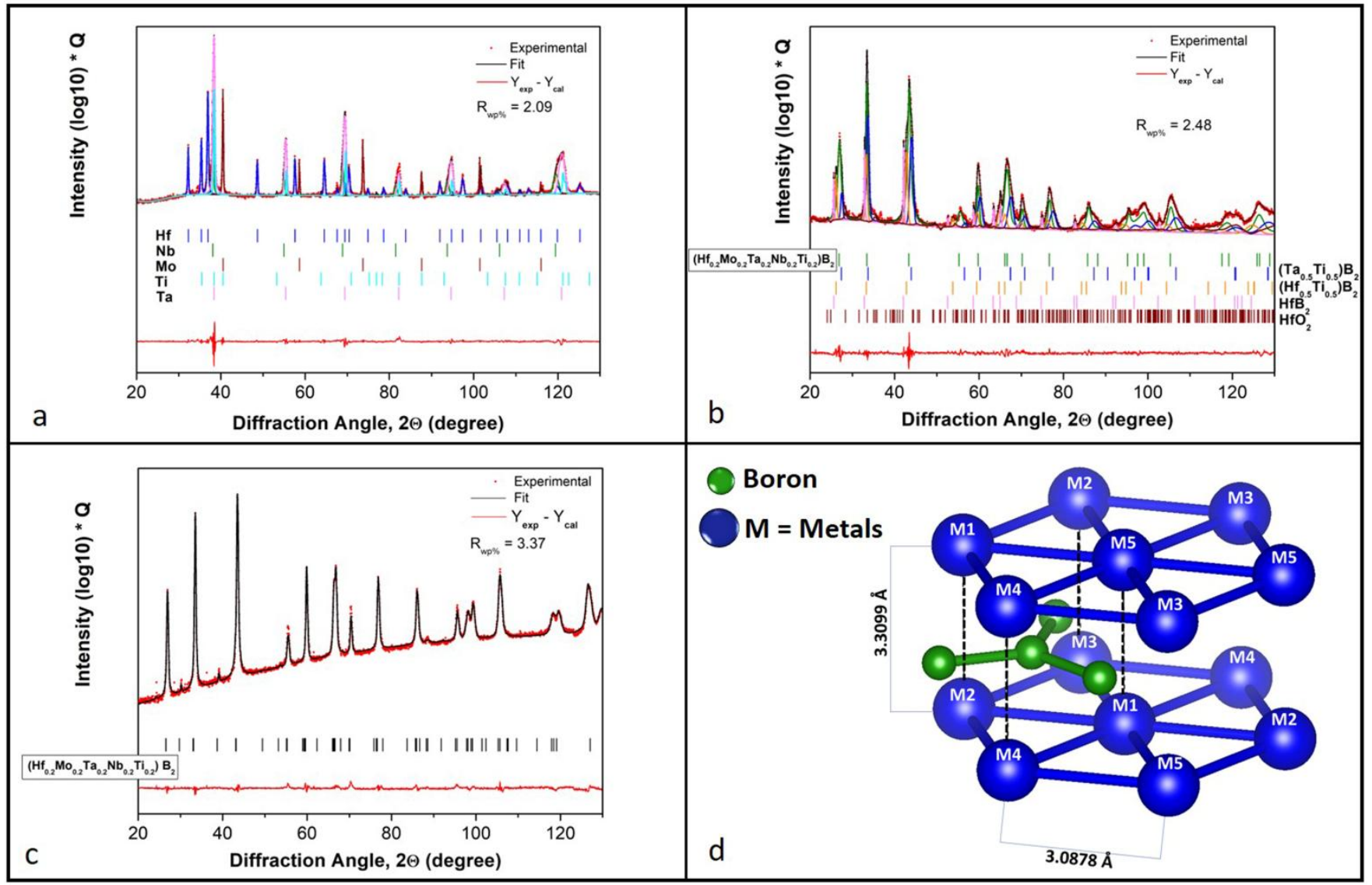

Fig. 2 


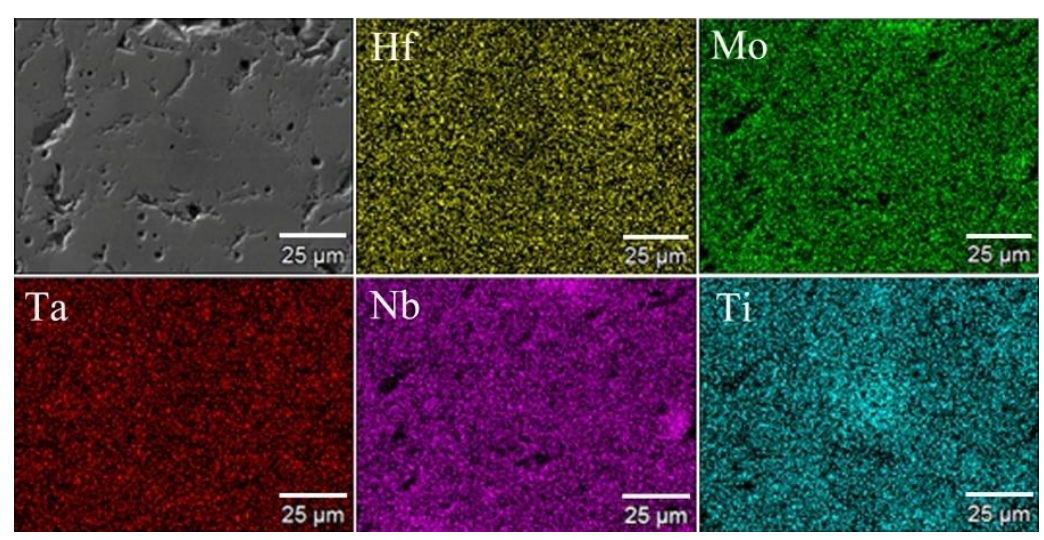

Fig. 3

18

19

20

21

22

23

24

25

26

27

28

29

30

31

32

33

34

35

36

37

38

39

40

41

42

43

44

45

46

47

48

49

50

51

52

53

54

55

56

57

58

59

60

61

62

63 
1 2

\title{
Novel Processing Route for the Fabrication of Bulk High-Entropy Metal Diborides
}

\author{
Giovanna Tallarita ${ }^{1}$, Roberta Licheri $^{1}$, Sebastiano Garroni ${ }^{2-3}$, Roberto Orrù ${ }^{1, *}$, Giacomo \\ $\mathrm{CaO}^{1}$ \\ ${ }^{1}$ Dipartimento di Ingegneria Meccanica, Chimica, e dei Materiali, Università degli Studi \\ di Cagliari, via Marengo 2, 09123 Cagliari, Italy \\ ${ }^{2}$ International Research Centre in Critical Raw Materials-ICCRAM, University of Burgos, Plaza Misael \\ Bañuelos s/n, 09001 Burgos, Spain \\ ${ }^{3}$ Advanced Materials, Nuclear Technology and Applied Bio/Nanotechnology, Consolidated Research \\ Unit UIC-154, University of Burgos, Hospital del Rey s/n, 09001 Burgos, Castilla y Leon, Spain
}

\begin{abstract}
A single high-entropy phase material with hexagonal structure is produced by a two-steps processing method. Elemental reactants are first remarkably converted by Self-propagating High-temperature Synthesis (SHS). The completion of the chemical transformation to the desired $\left(\mathrm{Hf}_{0.2} \mathrm{Mo}_{0.2} \mathrm{Ta}_{0.2} \mathrm{Nb}_{0.2} \mathrm{Ti}_{0.2}\right) \mathrm{B}_{2}$ phase and its concurrent consolidation up to $92.5 \%$ relative density is achieved by processing the SHS powders at $1950^{\circ} \mathrm{C}$ via Spark Plasma Sintering. It is clearly evidenced that the use of the SHS technique is extremely beneficial to promote the formation of high-entropy ceramics, as compared to the time consuming ball milling treatment alternatively adopted.
\end{abstract}

Keywords: High-entropy ceramics; Borides; Spark Plasma Sintering; Self-propagating Hightemperature Synthesis; X-ray diff raction (XRD).

* Corresponding author: Roberto Orrù - roberto.orru@ dimcm.unica.it 
The growing interest in Ultra-High Temperature Ceramics (UHTCs) based on transition metal diborides is readily justified by their unusual combination of attractive physico-chemical properties, such as melting temperature exceeding $3000 \mathrm{~K}$, high hardness, chemical inertness, good electrical and thermal conductivity, intrinsic solar selectivity, low neutron absorption, etc. [1]. Aerospace (wing leading edges, nosetips, etc.), solar energy (receivers for concentrating solar power plants), nuclear reactors, metallurgy (molten metal crucibles), cutting tools, microelectronics, etc., are only few examples of application fields where UHTCs are extremely desirable. In spite of this, a suitable diffusion of such material family is not reached yet, due to their relatively low fracture toughness and not adequate high temperature oxidation properties, other than because of the difficulties encountered for the obtainment of highly dense bodies.

In this context, a new emerging class of UHTCs, the so called High-Entropy Borides (HEBs) was recently developed at the University of California, San Diego (USA) [2]. HEBs belong to the more general family of high-entropy alloys, where metallic elements are properly combined in near equimolar ratios to generate new crystalline solid-solutions characterized by a maximum configurational entropy $\Delta S_{\text {mix }}=R \cdot \ln N$, where $R$ and $N$ are the gas constant and the total number of the equimolar components, respectively [3]. The strong interest in these materials stems from the improved thermal stability and strengthening they usually exhibit with respect to conventional alloys [3-5].

So far, the research activity in this field has been mostly focused on metallic phases, whereas only few and recent studies are available on high-entropy ceramics, either oxides [6-10] or non oxides [2,1115].

As for non oxides high entropy ceramics, six types of five-components HEBs have been prepared by Gild et al. [2]. The adopted process basically consisted of a co-milling treatment of their individual $\mathrm{MeB}_{2}$ constituents $(\mathrm{Me}=\mathrm{Zr}, \mathrm{Hf}, \mathrm{Ta}, \mathrm{Ti}, \mathrm{Mo}, \mathrm{Nb}, \mathrm{Cr})$ combined in equimolar proportions and the resulting powders were densified for $5 \mathrm{~min}$ by SPS at $2000^{\circ} \mathrm{C}$ and $30 \mathrm{MPa}$. The obtained products were single-phase materials, up to $92.4 \%$ dense, which display higher hardness and oxidation resistance as compared to the average properties of individual components fabricated and tested under the same conditions. Improved performances (hardness and thermal stability) were also reported when considering of HEB thin films prepared by non-reactive physical vapor deposition [13]. Similar findings were also obtained when characterizing the $99 \%$ dense equiatomic high-entropy carbides, namely (Hf$\mathrm{Ta}-\mathrm{Zr}-\mathrm{Nb}) \mathrm{C}$, produced very recently via SPS $\left(2300^{\circ} \mathrm{C}\right)$ from ball milled powders [11].

The major concern related to the previously mentioned fabrication methods is represented by the intense mechanical pre-treatment of the powder mixture requested to induce the formation of a single 
phase product during the subsequent densification stage. For instance, Gild et al [2] processed the diborides mixture for $6 \mathrm{~h}$ by high energy ball milling before SPS. Moreover, the duration of the mechanical treatment was even longer $(24 \mathrm{~h})$ for the fabrication of high-entropy carbides [11].

As a consequence, the corresponding whole processing time becomes very long. Furthermore, the extremely abrasive character of transition metal diborides and carbides makes the related powders prone to be contaminated from milling media, which certainly represents a crucial issue.

In this work, an alternative, more efficient, two-step processing method, consisting of the Selfpropagating High-temperature Synthesis (SHS) of the high entropy product followed by the SPS of the resulting powders, is proposed. While the latter approach was already successfully exploited for the obtainment of various standard monophasic and composite UHTCs [16], it is the first time that crystalline high entropy ceramics are produced following such route.

SHS experiments were performed starting from Hf (Alfa Aesar, cod. 00337, particle size $<44 \mu \mathrm{m}$,

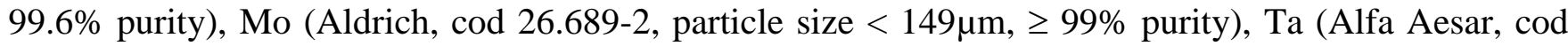

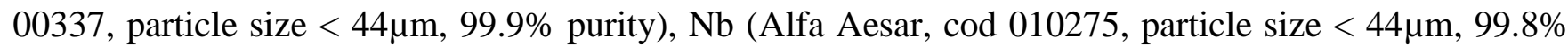

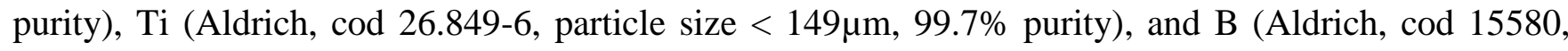
amorphous, $\geq 99 \%$ purity) powders. Mixing of reactants was carried out according to the following reactions stoichiometry:

$$
0.2 \mathrm{Hf}+0.2 \mathrm{Mo}+0.2 \mathrm{Ta}+0.2 \mathrm{Nb}+0.2 \mathrm{Ti}+(2+\mathrm{x}) \mathrm{B} \rightarrow\left(\mathrm{Hf}_{0.2} \mathrm{Mo}_{0.2} \mathrm{Ta}_{0.2} \mathrm{Nb}_{0.2} \mathrm{Ti}_{0.2}\right) \mathrm{B}_{2}
$$

The use of a slight excess of $\mathrm{B}(\mathrm{x}=0.2)$ with respect to the stoichiometric value allows for, in agreement to previous studies related to the obtainment of individual metal diborides [17-18], the removal of oxide impurities initially present in the raw powders. SHS experiments were conducted inside a closed stainless steel vessel under Argon atmosphere using cylindrical pellets (10 mm diameter and $30 \mathrm{~mm}$ high) obtained after cold-pressing about $10 \mathrm{~g}$ of the reactants mixture. The reaction was activated at one pellet end using an electrically heated tungsten coil.

The SHS product was pulverized after a short $(20 \mathrm{~min})$ ball milling treatment using a SPEX 8000 (SPEX CertiPrep, USA) shaker device with a ball-to-powder weight ratio of 2. Particle size of the resulting powders was evaluated by laser light scattering analysis (CILAS 1180, France). Their consolidation was carried out by SPS (515S model, Fuji Electronic Industrial Co., Ltd., Kanagawa, Japan) at $1950^{\circ} \mathrm{C}$ for 20 min under a mechanical pressure of $20 \mathrm{MPa}$ and vacuum conditions. Disks of about $14.7 \mathrm{~mm}$ diameter and $3 \mathrm{~mm}$ thickness were obtained. Details on the SPS apparatus and procedure can be found elsewhere [17-18]. 
Compositional and structural characterization of the SHS and SPS products was performed by X-ray diffraction analysis (Philips PW 1830, Netherlands) using $\mathrm{Cu} K_{\alpha}$ radiation, over a range of scattering angles $2 \theta$ from 20 to 130 , in steps of $0.05^{\circ}$ with $15 \mathrm{~s}$ acquisition time per angle. The XRD patterns were analyzed by the Rietveld method using the MAUD program to determine and quantify the phases content and the corresponding microstructural parameters [19]. In addition, the compositional uniformity in sintered samples was assessed by examining their cross section by high resolution scanning electron microscopy (HRSEM) (mod. S4000, Hitachi, Tokyo, Japan) equipped with a UltraDry EDS Detector (Thermo Fisher Scientific, Waltham, MA, USA).

As schematically represented in Figure 1, the first processing stage consists in the preparation of $\left(\mathrm{Hf}_{0.2} \mathrm{Mo}_{0.2} \mathrm{Ta}_{0.2} \mathrm{Nb}_{0.2} \mathrm{Ti}_{0.2}\right) \mathrm{B}_{2}$ by SHS according to reaction (1). The initial mixture, containing the starting reagents, has been analyzed by XRD. The pattern integrated with the Rietveld analysis is reported in Figure 2a, and it confirms the presence of the all metals with the expected concentration (see Table 1). Bragg reflections of Boron cannot be detected in this pattern because its amorphous nature and the low scattering, if compared with the other heavy metals. Upon ignition, the reaction front displayed a self-sustaining character with a measured maximum temperature of about $2000^{\circ} \mathrm{C}$ and average velocity of $4.75 \pm 0.25 \mathrm{~mm} / \mathrm{s}$. Such behavior was similar to that observed when the individual diborides were synthesized by SHS, for instance $\mathrm{HfB}_{2}$ [17], $\mathrm{TaB}_{2}$ [18] and $\mathrm{TiB}_{2}$ [20], and is consistent with their high enthalpies of formation $\left(-\Delta \mathrm{H}_{\mathrm{f}}^{0}\right)$, i.e. $335.975,209.200$ and $323.800 \mathrm{~kJ} / \mathrm{mol}$, respectively [21].

The particle size parameters of the powders obtained after the SHS products was comminuted by 20 min ball milling treatment are $\mathrm{d}_{10}=0.23 \pm 0.02 \mu \mathrm{m}, \mathrm{d}_{50}=1.94 \pm 0.14 \mu \mathrm{m}, \mathrm{d}_{90}=9.82 \pm 0.39 \mu \mathrm{m}$, and $\mathrm{d}_{\mathrm{av}}=3.71 \pm 0.20 \mu \mathrm{m}$. The XRD pattern of the synthesized powders is reported in Figure $\mathbf{2 b}$ along with the related best fit profile. The resulting compositional and microstructural data, as determined by Rietveld analysis, are summarized in Table 1. The reported results clearly indicate that a high conversion (about 96 wt.\%) of starting reactants to the desired phase was achieved by SHS. However, minor amounts of other diborides $\left(\left(\mathrm{Ta}_{0.5} \mathrm{Ti}_{0.5}\right) \mathrm{B}_{2},\left(\mathrm{Hf}_{0.5} \mathrm{Ti}_{0.5}\right) \mathrm{B}_{2}\right.$ and $\left.\mathrm{HfB}_{2}\right)$ and traces of metal oxides $\left(\mathrm{HfO}_{2}\right)$ have been also detected. The formation of the expected high-entropy solid solution ( $\mathrm{SG}=P 6 / \mathrm{mmm}$ ), nominally indicated by the formula reported in Eq. 1, can be proved by a direct comparison of the corresponding cell parameters reported in Table 1 with those ones provided by Gild et al. [2]. Nonetheless, as evidenced above, the obtainment of a single phase product was not fully achieved by SHS.

The combustion synthesized powders were then processed for $20 \mathrm{~min}$ at $1950^{\circ} \mathrm{C}$ by SPS. The XRD pattern of the cross section of the sintered sample is also shown in Figure 2c with the corresponding 
best-fit, while the related data are reported in Table 1. The obtained results indicated that the SPS treatment induced some compositional changes in the processing sample. More important is the fact that such transformations lead to massive product with neither secondary nor asymmetric peaks detected by XRD analysis. So, ultimately, a single phase material was finally obtained by SPS, as determined by the Rietveld analysis. It should be noted that XRD results for the sintered material are very similar to those ones reported by Gild et al. [2] for the same system. This confirms the formation of the high-entropy alloy characterized by 2D layers of metal cations, as schematically represented in Figure 2d [22]. The estimated value for the theoretical density of the HEB system under investigation, i.e. $8.56 \mathrm{~g} / \mathrm{cm}^{3}$, comparable to that one obtained by Gild et al. [2] $\left(8.67 \mathrm{~g} / \mathrm{cm}^{3}\right)$, further supports the latter statement. As a difference, it should be noted that the minor secondary phases evidenced in the latter study by XRD, and attributed to stable $\mathrm{HfO}_{2}$ and $\mathrm{ZrO}_{2}$, were not detected in the bulk sample produced in the present work. It is likely that the SHS process, and the corresponding conditions specifically adopted in the present investigation (excess of boron in Eq. 1), are highly beneficial in this regard. This holds also true when considering the traces $(0.1 \mathrm{wt} . \%)$ of $\mathrm{HfO}_{2}$ detected in SHS powders (Figure 2b) which are entirely eliminated during the subsequent SPS stage because of the likely presence of residual unreacted Boron. The end product reached relative density levels up to $92.5 \%$, comparable to the best values reported in Gild et al. [2]. The good densification as well as the uniform composition achieved is in agreement with the cross-sectional SEM micrograph reported in Figure 3 along with the related EDX maps. In particular, the latter ones testify that all the elements are very homogeneously distributed across the sample, with no specific evidence of preferential aggregation phenomena.

On the basis of the results discussed in this work, it is possible to state the SHS method represents a suitable tool for obtaining powders to be processed by SPS for the fabrication of innovative high entropy ceramics. In this regard, it is worth to mention the two key motivations generally provided to explain the high sintering ability displayed by UHTC powders when produced by SHS. The first one is related to the high defect concentrations associated to the extreme process conditions (heating and cooling rates on the order of $10^{5}$ and $10^{3} \mathrm{~K} / \mathrm{min}$, respectively) encountered during the fast propagation of the synthesis front [23]. In addition, when ceramic composites are synthesized, it is observed that stronger interfacial bonds are established between the fine grains of the different phases simultaneously formed in-situ, which lead to a reduction of the diffusion distances [24]. These aspects are also expected to play a beneficial role in promoting the atomic diffusion in SHS powders for the formation of the single phase HEBs during the SPS stage. It important to mention the fact that experiments conducted using the Reactive Spark Plasma Sintering (R-SPS) route, where the product synthesis and its consolidation are performed in a single 
stage as an alternative to the two steps SHS-SPS technique, did not allow us to reach the desired target. In addition, the R-SPS approach is often not appropriate when, as in the present case, strongly exothermic systems are taken into account, since various problems are usually encountered when the synthesis process occurs under the combustion regime inside a closed powder container [25].

Since the single phase material produced in the present work by SHS-SPS displays a relative density very close to that obtained by Gild et al. [2] for the same system, i.e. 92.5 and $92.2 \%$, respectively, it is expected that the corresponding properties will be also similar. In particular, a higher hardness was reported for the $\left(\mathrm{Hf}_{0.2} \mathrm{Mo}_{0.2} \mathrm{Ta}_{0.2} \mathrm{Nb}_{0.2} \mathrm{Ti}_{0.2}\right) \mathrm{B}_{2}$ material $(22.5 \pm 1.7 \mathrm{GPa})$ with respect to the average value of the individual metal diborides $(19.2 \pm 1.3 \mathrm{GPa})$ [2]. Improved oxidation resistance characteristics were also observed, based on the weight gains measured during isothermal tests conducted in the range 1000$1200^{\circ} \mathrm{C}$ for $1 \mathrm{~h}$ under flowing dry air, i.e. $\left(\mathrm{Hf}_{0.2} \mathrm{Mo}_{0.2} \mathrm{Ta}_{0.2} \mathrm{Nb}_{0.2} \mathrm{Ti}_{0.2}\right) \mathrm{B}_{2}<\mathrm{HfB}_{2}<\mathrm{TaB}_{2}<\mathrm{NbB}_{2}<\mathrm{TiB}_{2}$ [2]. Of course, the potential of this HEB for industrial applications can be better defined when residual porosity of the bulk sample will be reduced, so that the mechanical properties and oxidation resistance could be correspondingly improved. Thus, future work will be specifically addressed to the optimization of the SHS-SPS process conditions particularly aimed to further increase the relative density of the sintered material. The resulting product will be then subjected to a comprehensive characterization from the microstructural, mechanical, thermal, optical, etc., points of view, to possibly identify one or more suitable applications for this material.

In summary, our study demonstrates for the first time the feasibility of the fabrication of high entropy ceramics by coupling the SHS and SPS techniques. In particular, it is found that the $\left(\mathrm{Hf}_{0.2} \mathrm{Mo}_{0.2} \mathrm{Ta}_{0.2} \mathrm{Nb}_{0.2} \mathrm{Ti}_{0.2}\right) \mathrm{B}_{2}$ system was not obtained as a single phase by SHS, albeit a high conversion level (96 wt.\%) of the elemental reactants to the desired phase was reached. Nonetheless, when the resulting SHS powders were processed by SPS, a single phase bulk material was produced. The proposed process is undoubtedly more advantageous as compared to that adopted so far, where an intense mechanical pre-treatment of the individual borides was required before SPS. This feature certainly opens interesting perspectives for the exploitation of the huge potential of high entropy ceramics systems in both innovative and traditional fields.

\section{Acknowledgements}

One of the authors (G.T.) performed her activity in the framework of the International $\mathrm{PhD}$ in Innovation Sciences and Technologies at the University of Cagliari, Italy. 


\section{References}

[1] W.G. Fahrenholtz, G.E. Hilmas, Scripta Mater. 129 (2017) 94.

[2] J. Gild, Y. Zhang, T. Harrington, S. Jiang, T. Hu, M.C. Quinn, W.M. Mellor, N. Zhou, K. Vecchio, J. Luo, Sci. Rep. 6 (2016) 37946.

[3] Y.F. Ye, Q. Wang, J. Lu, C.T. Liu, Y. Yang, Mater. Today 19 (2016) 349

[4] D.B. Miracle, O.N. Senkov, Acta Mater. 122 (2017) 448.

[5] J. Chen, X. Zhou, W. Wang, B. Liu, Y. Lv, W. Yang, D. Xu, Y. Liu, J. Alloy. Compd. 760 (2018) 15.

[6] C.M. Rost, E. Sachet, T. Borman, A. Moballegh, E.C. Dickey, D. Hou, J.L. Jones, S. Curtarolo, J.P. Maria, Nat. Commun. 6 (2015) art. no. 8485;

[7] D. Bérardan, S. Franger, D. Dragoe, A.K. Meena, N. Dragoe, Phys. Status Solidi RRL 10 (2016) 328.

[8] D. Bérardan, S. Franger, A.K. Meena, N. Dragoe, J. Mater. Chem. A 4 (2016) 9536.

[9] J. Gild, M. Samiee, J.L. Braun, T. Harrington, H. Vega, P.E. Hopkins, K. Vecchio, J. Luo, J. Eur. Ceram. Soc. 38 (2018) 3578.

[10] S. Jiang, T. Hu, J. Gild, N. Zhou, J. Nie, M. Qin, T. Harrington, K. Vecchio, J. Luo, Scripta Mater. 142 (2018) 116.

[11] M. Castle, T. Csanádi, S. Grasso, J. Dusza, M. Reece, Sci. Rep. 8 (2018) 8609

[12] J. Dusza, P. Švec, V. Girman, R. Sedlák, E.G. Castle, T. Csanádi, A. Kovalčíková, M.J. Reece, J. Eur. Ceram. Soc. 38 (2018) 4303.

[13] P.H. Mayrhofer, A. Kirnbauer, P. Ertelthaler, C.M. Koller, Scripta Mater. 149 (2018) 93.

[14] Y.-P. Wang, G.-Y. Gan, W. Wang, Y. Yang, B.-Y. Tang, Phys. Status Solidi B (2018) 1800011 doi:10.1002/pssb.201800011

[15] X. Yan, L. Constantin, Y. Lu, J.-F. Silvain, M. Nastasi, B. Cui, J. Am. Ceram. Soc. (2018) doi: $0.1111 /$ jace. 15779

[16] R. Orrù, G. Cao, Materials 6 (2013) 1566.

[17] C. Musa, R. Orrù, D. Sciti, L. Silvestroni, G. Cao, J. Eur. Ceram. Soc. 33 (2013) 603.

[18] R. Licheri, C. Musa, R. Orrù, G. Cao, D. Sciti, L. Silvestroni, J. Alloy. Compd. 663 (2016) 351.

[19] L. Lutterotti, R. Ceccato, R. Dal Maschio, E. Pagani, Mater. Sci. Forum 87 (1998) 278.

[20] E. Sani, M. Meucci, L. Mercatelli, A. Balbo, C. Musa, R. Licheri, R. Orrù, G. Cao, Sol. Energy Mater Sol. Cells 169 (2017) 313.

[21] I. Barin, Thermochemical data of pure substances. VHC, Weinheim, Germany, 1989. 
[22] K. Momma, F. Izumi, J. Appl. Crystallogr. 44 (2011) 1272.

[23] S.K. Mishra, S. Das, L.C. Pathak, Mater. Sci. Eng. A 364 (2004) 249.

[24] R. Licheri, R. Orrù, C. Musa, G. Cao, Mater. Lett. 62 (2008) 432.

[25] R. Licheri, C. Musa, R. Orrù, G. Cao, J. Eur. Ceram. Soc. 35 (2015) 1129. 


\section{Figure captions}

Fig. 1. Schematic representation of the processing route adopted for the fabrication of high entropy ceramics.

Fig. 2. XRD patterns and related Rietveld refinements of a) the initial reactants mixture, b) SHS powders and c) SPS bulk product. d) Scheme of the atomic crystal structure of the high entropy alloy synthesized. The unit cell was designed by VESTA software [22].

Fig. 3. Cross sectional SEM micrograph and related EDX elemental maps of the HEB sample produced by SPS 


\begin{tabular}{|c|c|c|c|c|c|c|c|c|c|c|}
\hline Phase & $\%$ & $\mathbf{a}(\mathbf{A})$ & b $(\mathbf{A})$ & c (A) & $\boldsymbol{\beta}\left({ }^{\circ}\right)$ & Symmetry & $\begin{array}{l}\text { Space } \\
\text { Group }\end{array}$ & $\begin{array}{c}\text { Crystallite size } \\
\text { (̊̊) }\end{array}$ & Microstrain & $\begin{array}{c}\text { Unit cell } \\
\text { volume }\left(\AA^{3}\right)\end{array}$ \\
\hline $\mathrm{Ti}$ & 21.0 & 3.3075 & 3.3075 & 3.3075 & 90.00 & Cubic & Im-3m & 1985 & 0.0008 & 36.1826 \\
\hline $\mathrm{Ta}$ & 20.9 & 3.3185 & 3.3185 & 3.3185 & 90.00 & Cubic & Im-3m & 18159 & 0.0034 & 36.5448 \\
\hline Мо & 20.2 & 3.1476 & 3.1476 & 3.1476 & 90.00 & Cubic & Im-3m & 1441 & 0.0002 & 31.1845 \\
\hline $\mathrm{Hf}$ & 19.1 & 3.2006 & 3.2006 & 5.0705 & 90.00 & Hexagonal & $\mathrm{P} 63 / \mathrm{mmc}$ & 1125 & 0.0013 & 44.9826 \\
\hline $\mathrm{Nb}$ & 18.8 & 3.3404 & 3.3404 & 3.3404 & 90.00 & Cubic & Im-3m & 232 & 0.0001 & 37.2731 \\
\hline \multicolumn{11}{|c|}{ SHS powders } \\
\hline Phase & $\%$ & $\mathbf{a}(\AA)$ & b $(\AA)$ & c $(\AA)$ & $\boldsymbol{\beta}\left({ }^{\circ}\right)$ & Symmetry & $\begin{array}{l}\text { Space } \\
\text { Group }\end{array}$ & $\begin{array}{c}\text { Crystallite size } \\
\text { (Å) }\end{array}$ & Microstrain & $\begin{array}{c}\text { Unit cell } \\
\text { volume }\left(\AA^{3}\right)\end{array}$ \\
\hline$\left(\mathrm{Hf}_{0.2} \mathrm{Mo}_{0.2} \mathrm{Ta}_{0.2} \mathrm{Nb}_{0.2} \mathrm{Ti}_{0.2}\right) \mathrm{B}_{2}$ & 96.2 & 3.1001 & 3.1001 & 3.3127 & 90.00 & Hexagonal & P6/mmm; & 300 & 0.0044 & 27.5717 \\
\hline$\left(\mathrm{Ta}_{0.5} \mathrm{Ti}_{0.5}\right) \mathrm{B}_{2}$ & 2.3 & 3.0819 & 3.0819 & 3.2526 & 90.00 & Hexagonal & P6/mmm; & 1000 & 0.0073 & 26.7546 \\
\hline$\left(\mathrm{Hf}_{0.5} \mathrm{Ti}_{0.5}\right) \mathrm{B}_{2}$ & 0.9 & 3.1098 & 3.1098 & 3.4063 & 90.00 & Hexagonal & P6/mmm; & 1057 & 0.0052 & 28.5285 \\
\hline $\mathrm{HfB}_{2}$ & 0.5 & 3.1480 & 3.1480 & 3.4831 & 90.00 & Hexagonal & P6/mmm; & 1126 & 0.0014 & 29.8928 \\
\hline $\mathrm{HfO}_{2}$ & 0.1 & 5.1135 & 5.1345 & 5.4033 & 99.35 & Monoclinic & P21/c:b1 & 248 & 0.0019 & 139.9803 \\
\hline \multicolumn{11}{|c|}{ SPS product } \\
\hline Phase & $\%$ & $\mathbf{a}(\mathbf{A})$ & b $(\AA)$ & $\mathbf{c}(\AA)$ & $\beta\left({ }^{\circ}\right)$ & Symmetry & $\begin{array}{l}\text { Space } \\
\text { Group }\end{array}$ & $\begin{array}{c}\text { Crystallite size } \\
\text { (̊̊) }\end{array}$ & Microstrain & $\begin{array}{c}\text { Unit cell } \\
\text { volume }\left(\AA^{3}\right)\end{array}$ \\
\hline$\left(\mathrm{Hf}_{0.2} \mathrm{Mo}_{0.2} \mathrm{Ta}_{0.2} \mathrm{Nb}_{0.2} \mathrm{Ti}_{0.2}\right) \mathrm{B}_{2}$ & 100 & 3.0878 & 3.0878 & 3.3099 & 90.00 & Hexagonal & $\mathrm{P} 6 / \mathrm{mmm}$ & 869 & 0.0015 & 27.3303 \\
\hline
\end{tabular}




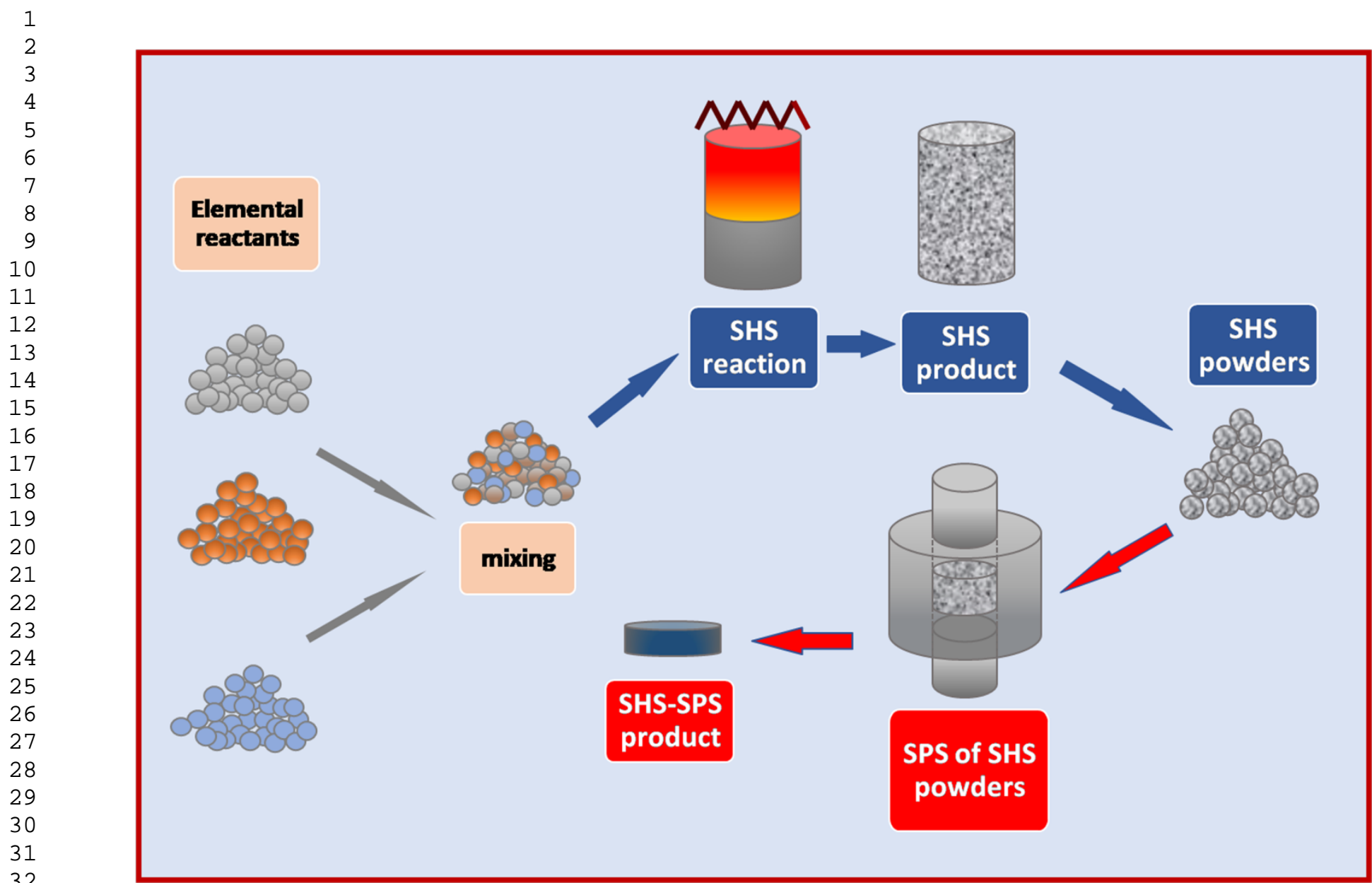

Fig. 1 
2

3

4

5

6

7

8

9

10

11

12

13

14

15

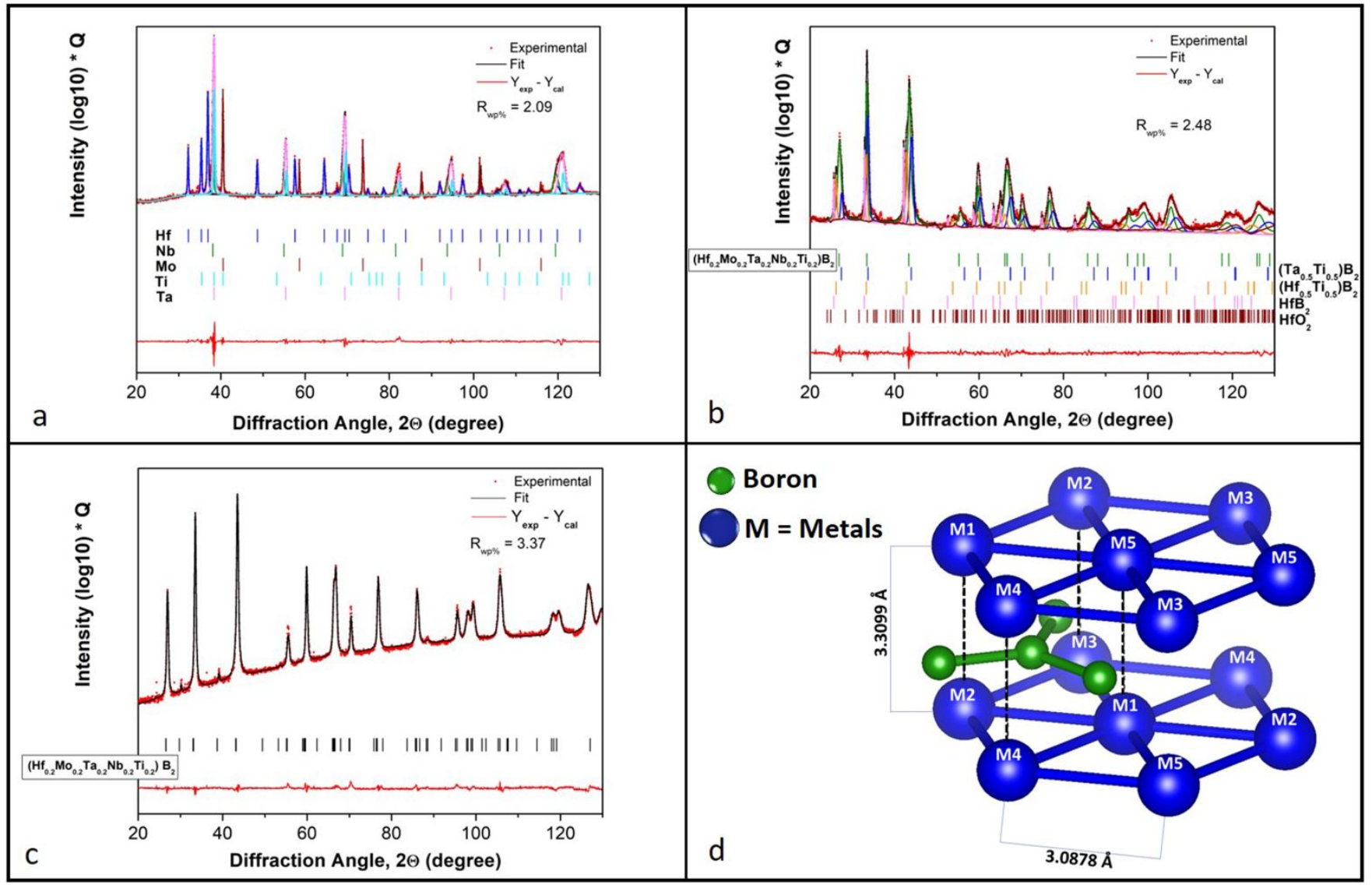

Fig. 2 


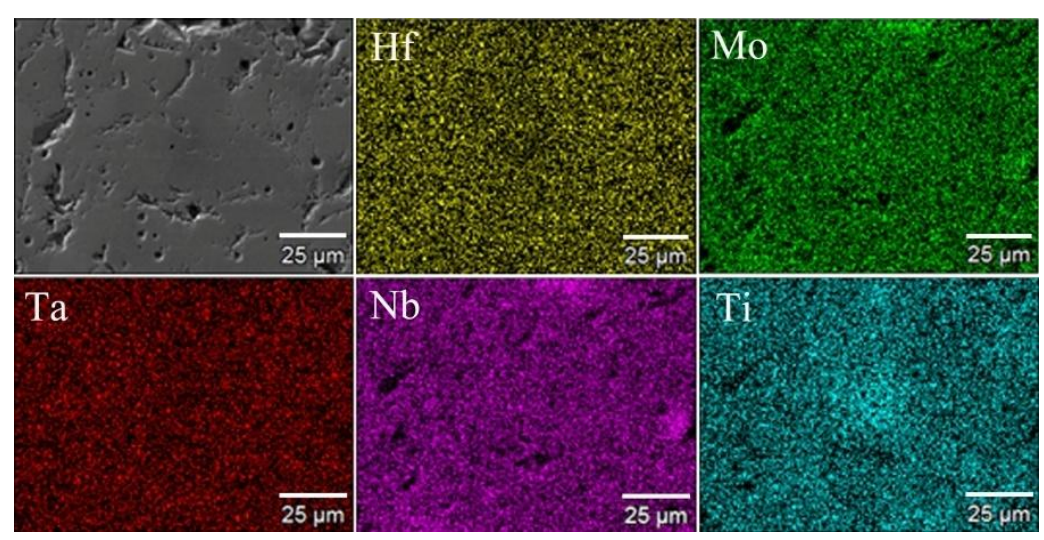

Fig. 3

18

19

20

21

22

23

24

25

26

27

28

29

30

31

32

33

34

35

36

37

38

39

40

41

42

43

44

45

46

47

48

49

50

51

52

53

54

55

56

57

58

59

60

61

62

63 


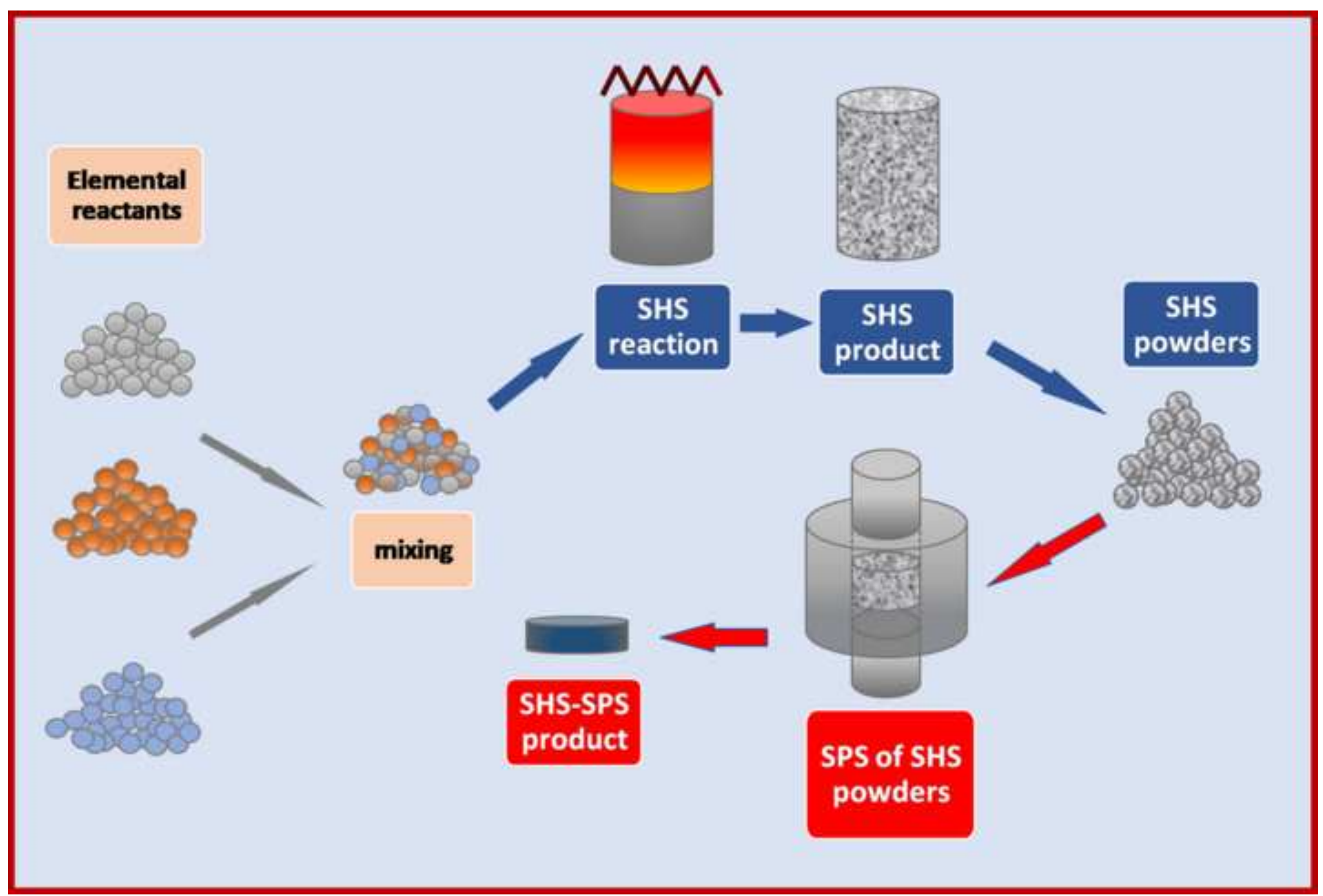




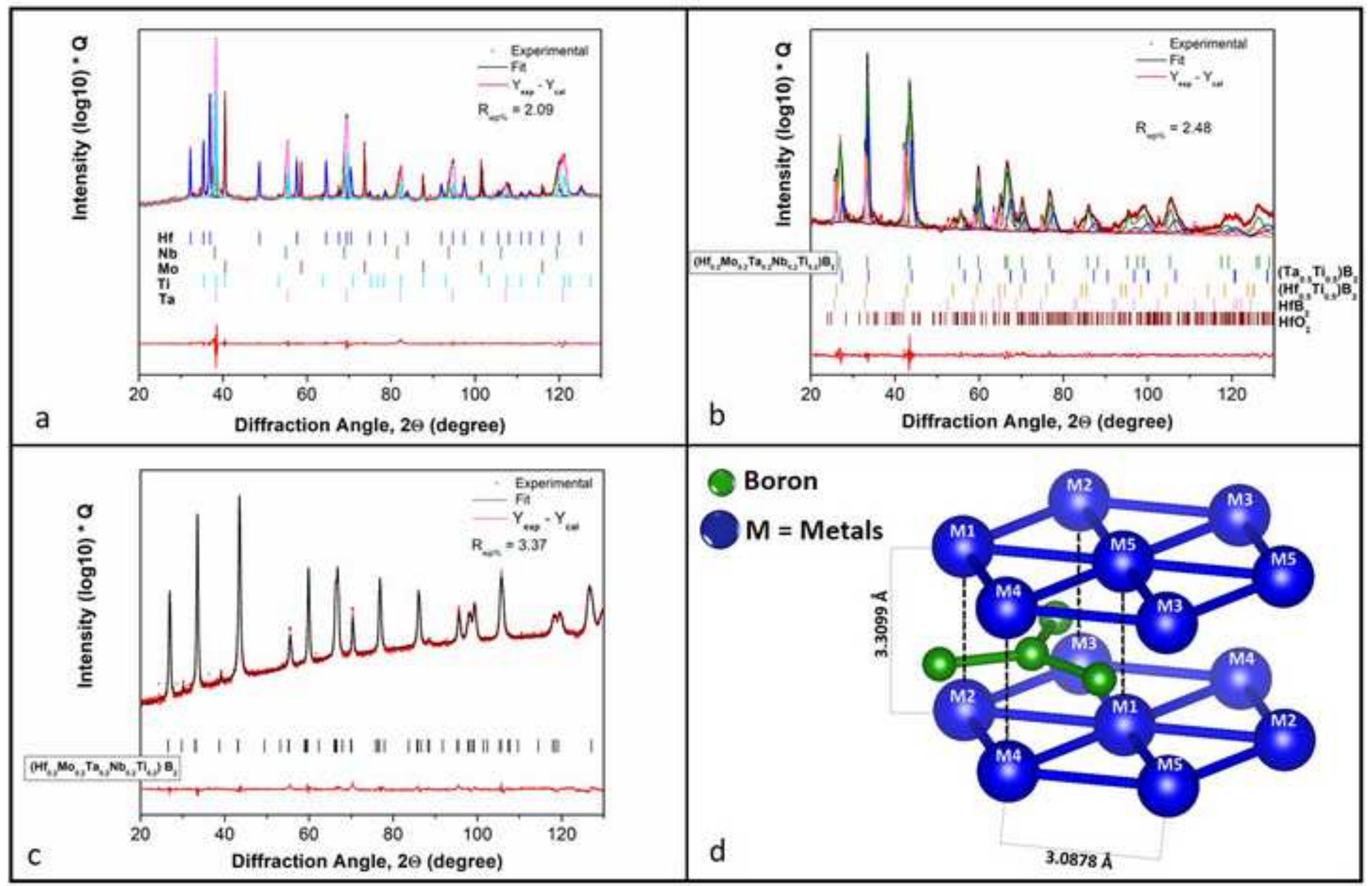


Click here to download high resolution image
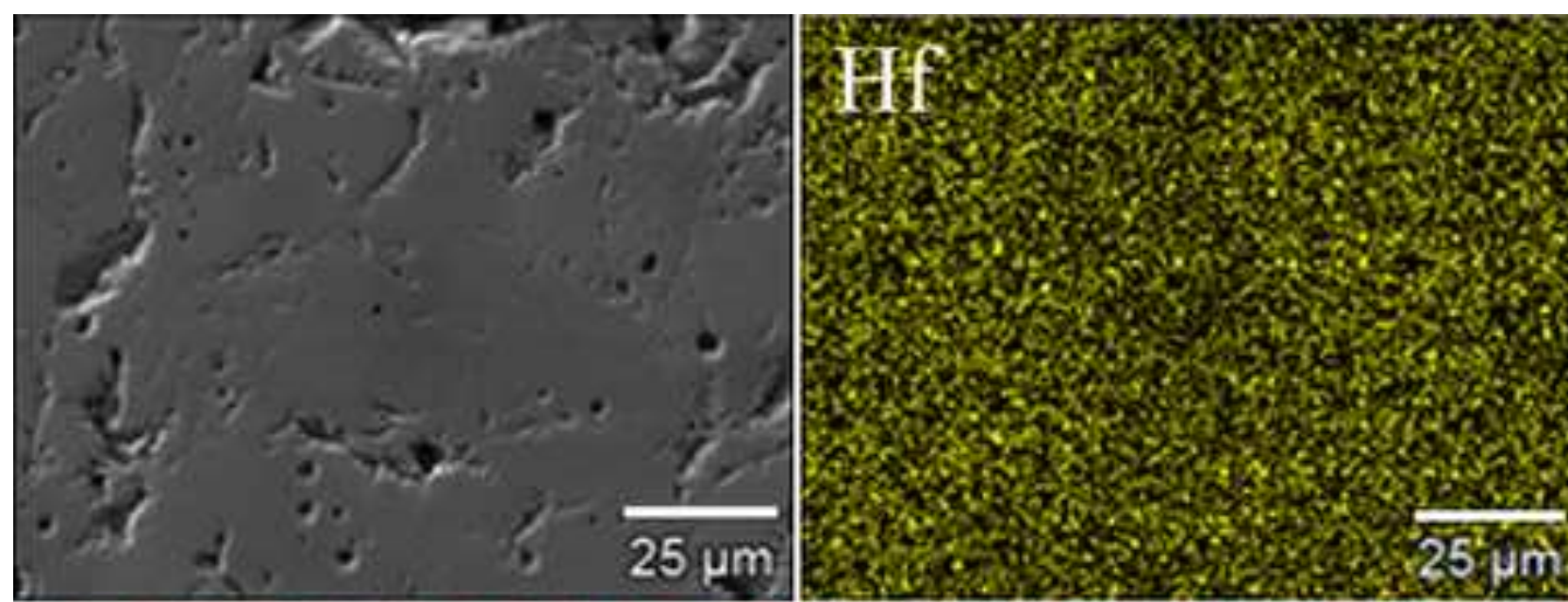

\section{Mo}

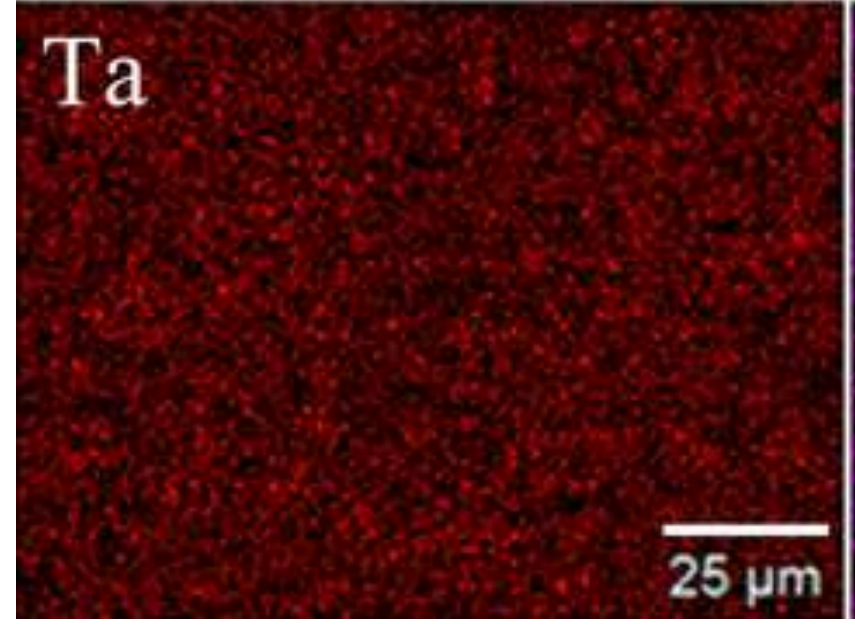

$\mathrm{Nb}$
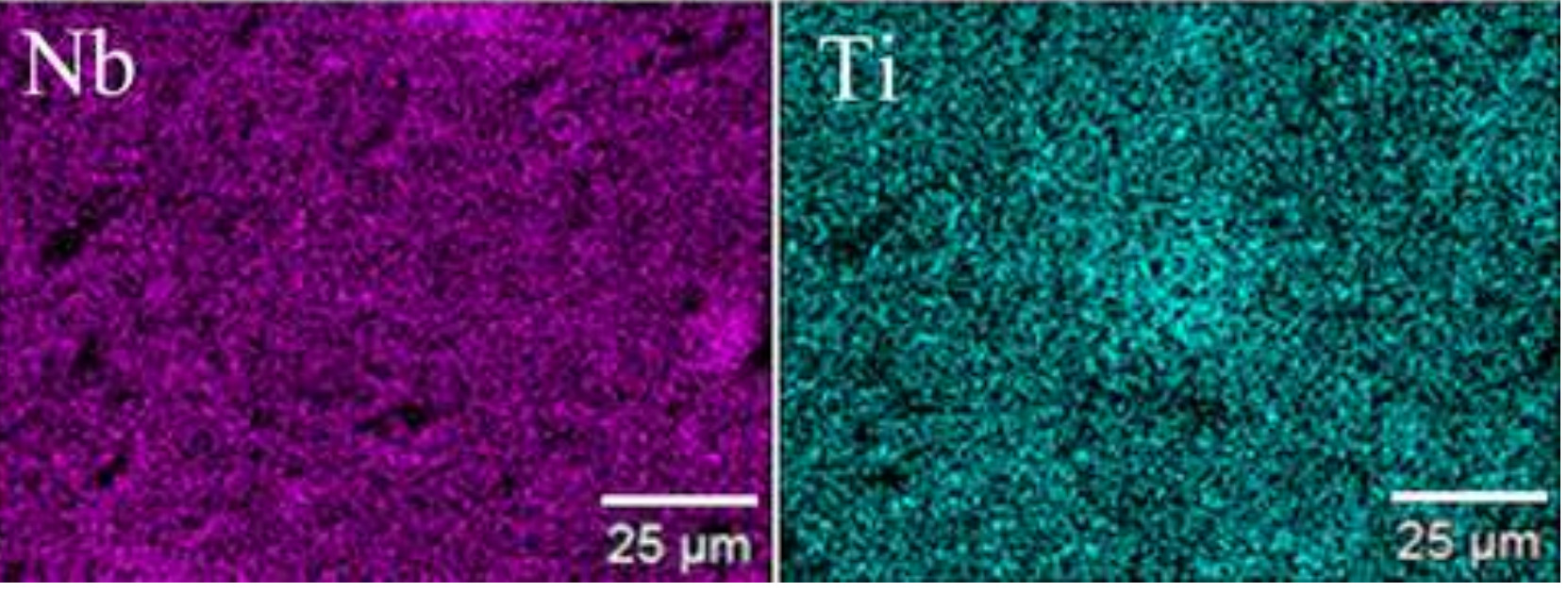

8.5.

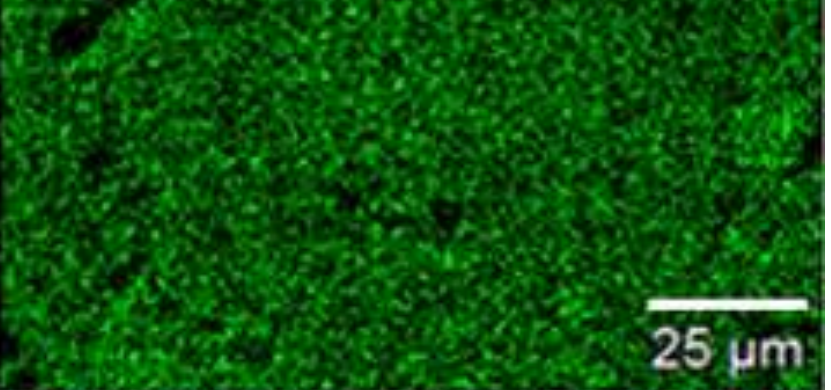

